\title{
Self Determination Theory and Preventive Care Delivery: A Research Involving Outpatient Settings Network (RIOS Net) Study
}

\author{
Andrew L. Sussman, PhD, MCRP, Robert L. Williams, MD, MPH, \\ Robert Leverence, MD, Park W. Gloyd, Jr, MD, MPH, and Benjamin F. Crabtree, PhD, \\ on Behalf of RIOS Net Clinicians
}

Purpose: Traditional approaches to improving preventive care have had limited success. In response, researchers have adopted new ways of examining the primary care environment and clinical encounters to better understand the factors that impact care delivery. We examined how clinicians make preventive counseling decisions to ascertain if self-determination theory (SDT) may further clarify influences on clinicians' decisions to take time for preventive counseling.

Methods: We studied clinical decision making through a mixed-method approach using obesity counseling as an example of preventive counseling. We conducted in-depth interviews and focus groups with 30 primary care clinicians in RIOS Net, a Southwestern US practice-based research network and distributed a survey, which was completed by $75 \%$ of 195 network members. We then used the components of SDT autonomy, competence, and relatedness to organize the factors that clinicians identified as most influential in their preventive counseling decisions.

Results: We found that SDT provides an organizing structure for understanding some of the psychology of clinicians' decisions to provide preventive counseling in the brief primary care encounter. In the specific case of obesity counseling clinicians expressed a high degree of autonomy, but barriers to competence and generally low levels of relatedness with professional colleagues seemed to limit their delivery of preventive counseling.

Conclusion: SDT provides a new perspective on factors that impact preventive counseling delivery, with a focus on the psychology of clinical decision making. Further research testing the predictive value of SDT may open new avenues for enhancing the delivery of preventive services. ( $\mathrm{J}$ Am Board Fam Med 2008;21:282-292.)

Despite advances that make it easier to disseminate information, streamline office systems, and implement quality improvement efforts, several indicators reveal little change in the overall delivery of

This article was externally peer reviewed.

Submitted 26 June 2007; revised 8 January 2008; accepted 11 January 2008.

From the Department of Family and Community Medicine (ALS, RLW) and the Department of Medicine (RL), University of New Mexico; the Albuquerque Service Unit, US Indian Health Service (PWG), Albuquerque; and the Department of Family Medicine, Robert Wood Johnson Medical School, University of Medicine and Dentistry of New Jersey (BFC), Piscataway.

Funding: This project was supported by grant number 5 R21 HS013496 from the Agency for Healthcare Research and Quality and grant number 8 D 54 HP 00032-04 from the Health Resources and Services Administration.

Conflict of interest: none declared.

Corresponding author: Andrew L. Sussman, PhD, MCRP, Family and Community Medicine, MSC 09-5040, 1 University of New Mexico, Albuquerque, NM 87131-0001 (E-mail: asussman@salud.unm.edu). preventive care. ${ }^{1-8}$ Previous efforts to improve the delivery of preventive care have typically focused on enhancing the performance of various individual components within the primary health care system or have aimed to optimize the functioning of the entire system. Not withstanding these comprehensive efforts at system-level modification, results have generally been disappointing. ${ }^{9-11}$ Such outcomes have led researchers to look beyond broad system-level influences on preventive care delivery to consider determinants at other levels of the care delivery process. ${ }^{12-14}$

Recent research aimed at improving preventive care delivery has been focused at the level of the individual primary care practice. ${ }^{15-17}$ Stange and colleagues ${ }^{18}$ have demonstrated that sustained enhancements in clinical preventive care delivery can be gained from practicelevel interventions molded to the unique and complex circumstances of individual practices. ${ }^{5,18}$ 
We recently began to examine influences on preventive care that operate at a third level, that of the individual clinician patient encounter. ${ }^{19} \mathrm{We}$ identified factors in the encounter that seem to affect clinicians' decisions to deliver, in this case, obesity counseling when faced with the many competing demands present in the brief patient encounter. Both relatively stable factors (such as available community resources) and more dynamic, situational factors (such as the patient's agenda for the visit) seem to influence whether and to what extent obesity counseling is provided.

Further analysis of these data led to an examination of a set of factors influencing preventive care delivery that seem to operate at a fourth clinician level, complementary to those operating at the system, practice, and encounter levels. To better understand how this set of clinician-level factors may operate, we turned to a well-known model of human motivation called self-determination theory (SDT). ${ }^{20-24}$ For over 30 years SDT has been used to examine the conditions that sustain and inhibit human motivation. SDT suggests that 3 elements are essential to achieving optimal motivation to action: (1) the need for autonomy having a sense of choice in our actions; (2) the need for competen$c e$ the desire to act proficiently in our surroundings; and (3) the need for relatedness the importance of feeling supported and connected with others. ${ }^{20,24}$ In recent years, SDT has been increasingly applied to clinical research in primary care. ${ }^{25-27}$

Here we describe how SDT as a conceptual model may clarify clinician-level factors that influence preventive care delivery by examining the psychology of clinicians' decision making. Using obesity counseling as a case study, we gathered data from a variety of clinicians in a practice-based research network. Our specific research question was whether the principal factors identified as influencing clinicians' decisions to provide obesity counseling were consistent with SDT.

\section{Methods}

\section{Study Design and Setting}

We conducted a mixed-methods study, conducting qualitative in-depth interviews and focus groups followed by a quantitative network survey. The data collection sequence was initially designed to elicit the factors that clinicians perceive as influences in their preventive counseling decisions. The research team included a medical anthropologist, a family physician, an internist, and a pediatrician.

The study was conducted in Research Involving Outpatient Settings (RIOS) Net, a practice-based research network in New Mexico. The more than 200 member clinicians of RIOS Net are $58 \%$ family practitioners, $8 \%$ general internists, $19 \%$ general pediatricians, and $15 \%$ nurse practitioners and physician assistants practicing in community health centers, Indian Health Service clinics, and University of New Mexico primary care sites serving lowincome, predominantly Hispanic and Native American communities. RIOS Net members are 50\% female, have a median age between 40 and 49, and are 74\% non-Hispanic White, 19\% Hispanic, 5\% Asian-American, and 2\% American Indian. For additional information about RIOS Net, please go to http://hsc.unm.edu/rios/.

\section{Overall Analytic Goal}

We first identified data themes related to obesity preventive counseling decisions and then examined the data in light of the 3 principal components of the SDT model: autonomy, competency, and relatedness. The goal was to explore whether SDT could provide assistance in understanding clinician decisions to provide preventive counseling in the brief encounter.

\section{Data Collection and Analysis}

Data collection followed a 3-step sequential process. During step 1 we conducted individual, indepth interviews ${ }^{28}$ with RIOS Net clinicians, purposefully sampling based on a set of factors we believe guide preventive counseling decisions: clinician type (mid-level practitioner, family physician or internist, and pediatrician); type of setting (community health center, Indian Health Service, and academic); practice location (rural and urban); and years of practice experience.

We developed a semistructured interview guide designed to elicit clinician narratives about their preventive counseling decisions during the brief encounter, basing the discussion on obesity counseling (Appendix 1). Six pilot interviews were conducted with other RIOS Net clinicians. Interviews were all conducted by one member of the research team (AS) and lasted between 45 and 60 minutes. All interviews were audiotaped and transcribed. After an immersion crystallization process, each member of our research team reviewed sets of 2 or 
3 transcripts. ${ }^{29}$ We met to read through the interviews together, identify emergent themes, and modify the sampling strategy and interview guide as needed. All transcripts were imported into NVivo software (QSR International, Australia) for further coding and to facilitate text retrieval. ${ }^{30}$ Data collection and analysis continued iteratively until the research team agreed that data saturation had been achieved.

During step 2 of the process, we conducted 2 "analytic" focus groups with 10 RIOS Net clinicians to further refine and evaluate our preliminary analytic framework. We selected participants using the same sampling criteria outlined above. We presented each group with a summary of the interview findings and solicited comments and reactions. Each group was audiotaped and transcribed. Using a template organizing style, we compared the focus group responses to our analytic framework, seeking responses that were either disconfirming or not included in the in-depth interviews. ${ }^{31}$ Transcripts were again imported into NVivo.

A survey was mailed to all RIOS Net clinicians as step 3 of our process. We developed the survey to confirm preliminary findings from the qualitative data (Appendix 2). We first piloted the survey with 13 clinicians and made necessary modifications before dissemination. Customary mail survey protocol was followed, using electronic communication and 3 random drawings for gift certificates to enhance response rates. A database created specifically for this study was used to enter responses, with $10 \%$ re-entered for a reliability check. A range of analytic techniques, including descriptive, bivariate, and multivariate, were used to characterize the sample and to assess the influence of specified preventive counseling factors. Further details regarding study methods are provided elsewhere. ${ }^{19}$

\section{Application to SDT}

The final analytic step involved comparing the data to the 3 principal domains of SDT. These domains autonomy, competence, and relatedness were used as a template to guide this process. The research team examined the degree to which the interpretive themes from the data matched the key elements of each SDT domain. The qualitative analyst used NVivo to identify data from the interviews and focus groups that served as a basis for further review. Findings from the network survey were then integrated into this new analytic framework to assess the degree to which they either supported and/or disconfirmed the application of SDT.

\section{Results}

\section{Demographics}

We interviewed 20 clinicians and conducted 2 focus groups with an additional 10 participants. Collectively, these clinicians had between 1 and 25 years of clinical experience and included 10 family physicians, 7 pediatricians, 4 internists, 6 physician assistants, and 3 nurse practitioners. The survey response rate was $75 \%$ (146 of the 195 RIOS Net members at the time of the study). These respondents were $57 \%$ family physicians, $22 \%$ pediatricians, $12 \%$ mid-level practitioners, and $9 \%$ internists. The majority $(72 \%)$ had $\geq 5$ years of experience after residency; $36 \%$ were from the University of New Mexico, 35\% where from Indian Health Service, $25 \%$ were from community health centers, and $4 \%$ were from private practice. Fifty-three percent of the respondents were female. See Table 1 for additional demographic details for each sample group.

\section{Factors that Influence Clinician Decision-Making in the Brief Encounter}

\section{Autonomy}

A principal theme in the data fit well with the SDT component of autonomy. Clinicians expressed a strong sense of autonomy (acting out of personal choice) with regard to their motivation and commitment to deliver preventive counseling for obesity. They consistently and firmly expressed their choice to address weight concerns in the brief encounter, despite the limitations of and barriers to that counseling.

"I'm sure if we went back and tried to gather stats it's probably not the best use of time but I'm not willing to stop. I still want to make the effort and try and occasionally there's a patient that seems to grab hold of the idea."

Results from the network survey corroborated this finding. Clinicians were asked to select the single most important factor in their decision to spend time on obesity from a menu of options that ranged from individual to professional (ie, clinical guideline) options. The majority of clinicians $(64 \%)$ indicated that they chose to engage in obesity preventive counseling "because of my personal 


\begin{tabular}{|c|c|c|c|}
\hline & $\begin{array}{l}\text { Clinician Interviews } \\
\qquad(\mathrm{n}=20)\end{array}$ & $\begin{array}{l}\text { Focus Groups } \\
\quad(\mathrm{n}=10)\end{array}$ & $\begin{array}{l}\text { Network Survey } \\
\quad(\mathrm{n}=146)\end{array}$ \\
\hline \multicolumn{4}{|l|}{ Gender } \\
\hline Female & 9 & 4 & 77 \\
\hline \multicolumn{4}{|l|}{ Practice specialty } \\
\hline Family physicians & 5 & 5 & 83 \\
\hline Pediatricians & 5 & 2 & 32 \\
\hline Mid-level practitioners (PA, NP) & 7 & 2 & 18 \\
\hline Internists & 3 & 1 & 13 \\
\hline Totals & 20 & 10 & 146 \\
\hline \multicolumn{4}{|l|}{ Institutional setting } \\
\hline University of New Mexico & 9 & 4 & 54 \\
\hline Community Health Center & 6 & 4 & 35 \\
\hline Indian Health Service & 5 & 2 & 51 \\
\hline Private practice & 0 & 0 & 6 \\
\hline Totals & 20 & 10 & 146 \\
\hline
\end{tabular}

PA, physician assistant; NP, nurse practitioner.

belief that the nonobese have a better quality of life." Although we did not specifically explore the basis for this strong intrinsic motivation, we attribute it to a shared set of values that unite clinicians in their mission to improve health and a sense of the importance of this health problem. Clinicians expressed their choice to provide obesity counseling in terms of their roles as primary care providers and the opportunity to form meaningful relationships with patients.

"Ob, I think it's worthwbile... I don't think it's because I've sat down and read 14 articles that obesity is a bad thing. I think it's because as you work with people and you hear what they're saying, it's an issue and so it probably is out of personal motivation and again the relationship of doctor to patient that you have.

\section{Competence}

Other principal themes in the data related directly to the SDT component of competence. We found that factors both within and external to the clinical setting presented critical barriers to the clinician's sense of competency (ability to achieve a desired outcome and to operate successfully in a given setting) in obesity preventive counseling. Clinicians cited barriers within the clinic setting, including lack of effective counseling strategies and competing demands for use of time within the brief encounter. They expressed deep frustration with ineffective counseling strategies and outcomes for sustained weight loss.
"I just haven't seen it be very successful with very many people unless they come in motivated to lose weight. I mean the reality is, you know, from everywhere you look, weight loss doesn't work very well for most people."

Factors external to the clinic setting, such as patient socioeconomic circumstances and the general lack of community resources, also presented obstacles that diminished clinician sense of competency, and thereby their willingness to engage in preventive obesity counseling. We found that clinicians felt ill-equipped to address the root causes of obesity residing in cultural, political and economic processes outside their purview.

"Probably I don't bring it up (obesity) as often as it needs to be because it feels overwhelming to me as well. One is the issue of poverty and learning healthy eating and changing habits among all the other issues that these people have. It just feels like I'm sort of adding one more burden to them at times."

"Obesity in children and adolescents is probably our most common problem and... it's one of the hardest to get a handle on how to effectively deal with it. I can't write them an antibiotic or cough medicine, it's not something that I can just write a script for. It's a societal problem, it's a familial problem and it's just been hard to try to determine the most effective way to deal with it and I'm still grappling with that."

In the network survey, respondents were asked to rank a list of 3 items that would be most influential in preventing obesity. Each of the clinicians' 
most common choices directly related to strategies for increasing competence. Reflecting the sense that societal issues were preeminent in the obesity problem, the clinicians first choice was to join community or legislative advocacy groups, followed by enhancing clinic services and, lastly, improving individual obesity counseling skills.

\section{Relatedness}

In our interviews, we found that relatedness (the desire to achieve meaningful relationships and belongingness) opportunities regarding obesity prevention counseling were generally lacking within the clinicians' practice settings.

"I don't have much time to sit around and talk with my colleagues, which is unfortunate. You know, maybe a little social chit-chat is the best I can do but we don't sit around and talk about clinic issues. . well, we do talk about practice issues; but obesity we haven't particularly talked about any time recently that I can remember. So my primary emphasis comes from reading I've done rather than talking with other providers."

In the network survey, only $2 \%$ selected the statement "Interactions with my colleagues have influenced me to do so" as the most important factor in their decision to provide obesity counseling.

Apart from relationships within the practice setting, there are additional challenges to maintaining relatedness with the broader health community in a large and mostly rural state like New Mexico. Clinicians may have very few colleagues within their clinic setting (some have none) and, given these conditions, have even more limited opportunities for professional exchange. In what might be considered to be relatedness to the broader community outside their professional colleagues, clinicians also expressed interest in participating in communitybased outreach and advocacy efforts aimed at obesity prevention. However, time constraints associated with busy, primary care practices in underserved settings limited their ability to achieve relatedness in this manner.

\section{Discussion}

We found that major themes expressed by clinicians in discussions about their approaches to obesity counseling fit well with SDT. This suggests that SDT may have explanatory value in understanding clinician decisions and limitations when providing preventive counseling in the brief primary care encounter. After examining clinicians' approaches to obesity counseling, we found that they expressed a strong sense of personal choice (autonomy) in their motivation to engage in obesity counseling. However, they described several things that diminish their sense of competency in these efforts, including a lack of effective counseling approaches, overwhelming societal barriers, and few external resources. The competing demands present in busy primary care practice settings along with geographic constraints limit clinicians' opportunities to develop and sustain relatedness with either professional colleagues or within the broader community. When viewed collectively, SDT factors of autonomy, competency, and relatedness offer a new perspective about reported low rates of preventive counseling for obesity in primary care. Our findings suggest that high levels of autonomy and internal motivation are not sufficient to sustain counseling efforts without effective and appropriate tools and without opportunities for relevant interactions with colleagues or community members.

Traditional approaches to improving primary care services have viewed the delivery of care as a machine made up of distinct yet interconnected parts: the health care system, the individual practice, and the clinical encounter. ${ }^{9,32}$ Care improvement interventions have targeted each of these levels of organization and have been designed to ensure that each part of the process performs optimally, thereby ensuring organizational efficiency. $^{33-35}$

SDT emphasizes another important level in efforts seeking to improve care delivery: the cognitive psychology of clinician decision making. This implies a new perspective whereby a clinician's actions are understood to be influenced not only by the health care system, practice, and encounter, but also by the social and cognitive contexts in which a given professional activity takes place. Decisions under the pressures of the brief clinical encounter are affected by the relationships between the "parts" of components in each level.

SDT may hold its greatest potential value as a way to synthesize newer approaches (ie, complexity science) seeking to understand practice dynamics and clinical decision making within primary care. ${ }^{15-17,36}$ SDT is based on the premise that all of us require a basic set of psychosocial inputs that are vital to our optimal functioning. ${ }^{24}$ These inputs are 
mediated both by our own individual needs and experiences as well as through the social/professional environments in which we operate. Given the multiple competing demands of the primary care environment, clinicians are increasingly required to make counseling decisions among numerous potentially beneficial options. By considering the cognitive psychology of clinician decision making, we believe that SDT provides a useful conceptual model to better understand factors that influence clinical decisions.

\section{Application}

In this study we have focused on the utility of SDT concepts as an explanatory framework for developing a richer understanding of clinician decision making. We also believe that SDT may provide guidance for preparing tailored interventions aimed at enhancing delivery rates of preventive services and for testing those interventions.

The interrelated SDT concepts of autonomy, competence, and relatedness seem to have implications for examining clinician behavior in the context of efforts to enhance the delivery of preventive counseling. In this study, clinicians identified a low level of competency as a principal factor limiting their decisions to engage in obesity preventive counseling. In another publication resulting from this study we found a lack of fit between leading national obesity guidelines and the experiences of primary care clinicians. ${ }^{37}$ Clinicians indicated that it was difficult to implement these guidelines in their practice settings because of the impact of cultural and societal factors over which they have little control (eg, unavailability of healthy foods). When viewed through an SDT "lens," infeasible guidelines that do not enhance competency may also diminish autonomy by limiting clinicians' ability to internalize their value. In addition, if the guidelines do not address a need for relatedness with colleagues and/or community members, they may also lessen their impact on care.

Lastly, perspectives within SDT may also provide insight into broader efforts to redesign and reform the health care system. For example, initiatives such as Prescription for Health, the Chronic Care Model, and pay for performance programs call for fundamental changes in the care delivery process and the prioritization of performance measures. ${ }^{38,39}$ In addition to evaluating the impact of these initiatives on system-, practice-, and patient- level outcomes, it may also be important to assess, using SDT concepts, how such externally imposed changes affect the psychological needs of the clinician. Further research, however, is first needed to formulate and test hypotheses suggested by this study. Which SDT domains are most relevant to clinical decision making? Does SDT have predictive value with clinician behavior in preventive counseling? If so, can interventions based on SDT lead to enhanced delivery of preventive care? Do clinicians vary (ie, individually or by training background) in the level of autonomy, sense of competence, or sense of relatedness they need to motivate action?

\section{Limitations}

Although we believe that many of the factors we identified are not unique to obesity counseling, it is possible that our findings are indeed unique to this preventive counseling topic. A recent study, however, supports the view that SDT can help explain provider behavior with other preventive counseling topics (eg, tobacco cessation). ${ }^{40} \mathrm{We}$ also note that the members of our practice-based research network are all in one state and practice in settings that differ from those of many primary care clinicians. It is possible that these practice characteristics create circumstances that make SDT seem more relevant to clinician decisions. Therefore, although we believe that the role of factors elucidated by SDT in clinician decision making are not unique to practice setting, further research is needed to explore how widely applicable SDT is to understanding clinician decision making both across clinical topics and across community and practice settings. Finally, it is possible that SDT is not the only theory of cognitive psychology that can explain clinician decision making. However, it is a leading theory in this area. Most importantly, it provides a structure for beginning to consider this new level of factors that influence the delivery of preventive counseling.

\section{Conclusion}

In recent years, new ideas drawn from a range of disciplines have injected fresh perspectives into the conceptualization of preventive care delivery and clinical decision making. SDT offers another, complementary framework that provides a unique "lens" with which to better understand the under- 
lying motivation that clinicians have toward particular counseling activities and how conditions in their environment either facilitate or constrain these natural tendencies. Preliminary findings are compelling, but future research will be needed to test these ideas and translate them into strategies that impact clinical practice.

We acknowledge and appreciate the RIOS Net clinicians who gave their time to participate in this study.

\section{References}

1. Eccles M, McColl E, Steen N, et al. Effect of computerised evidence based guidelines on management of asthma and angina in adults in primary care: cluster randomised controlled trial. BMJ 2002;325: 941.

2. Hunt DL, Haynes RB, Hanna SE, Smith K. Effects of computer-based clinical decision support systems on physician performance and patient outcomes. JAMA 1998;280:1339-46.

3. Hetlevik I, Holmen J, Krüger Ø, et al. Implementing clinical guidelines in the treatment of diabetes mellitus in general practice. Evaluation of effort, process and patient outcome related to implementation of a computer-based decision support system. Int J Tech Assess Health Care 2000;16:210-27.

4. Greco PJ, Eisenberg JM. Changing physicians' practices. N Engl J Med 1993;329:1271-4.

5. Goodwin MA, Zyzanski SJ, Zronek S, et al. A clinical trial of tailored office systems for preventive service delivery: the Study To Enhance Prevention by Understanding Practice (STEP-UP). Am J Prev Med 2001;21:20-8.

6. Cohen D, DiCicco-Bloom B, Strickland PO, et al. Opportunistic approaches for delivering preventive care in illness visits. Prev Med 2004;38:565-73.

7. Grimshaw JM, Shirran L, Thomas R, et al. Changing provider behavior: an overview of systematic reviews of interventions. Med Care 2001;39:II2-45.

8. Oxman AD, Thomson MA, Davis DA, Haynes RB. No magic bullets: a systematic review of 102 trials of interventions to improve professional practice. CMAJ 1995;153:1423-31.

9. Anderson RA, Crabtree BF, Steele DJ, McDaniel RR. Case study research: the view from complexity science. Qual Health Res 2005;5:669-85.

10. Institute of Medicine. Crossing the quality chasm: a new health system for the 21 st century. Washington, DC: National Academy Press; 2001.

11. Wunderlich GS, Kohler PO. Improving quality in long-term care. Washington, DC: National Academy Press, Division of Health Care Services; 2001.

12. Crabtree BF, Miller WL, Tallia AF, et al. Delivery of clinical preventive services in family medicine offices. Ann Fam Med 2005;3:430-5.
13. Cohen D, McDaniel RR Jr., Crabtree BF, et al. A practice change model for quality improvement in primary care practice. J Healthc Manag 2004;49: 155-168.

14. Stroebel CK, McDaniel RR Jr, Crabtree BF, et al. Using complexity science to inform a reflective practice improvement process. Jt Comm J Qual Patient Saf 2005;31:438-46.

15. Miller WL, McDaniel RR Jr., Crabtree BF, Stange KC. Practice jazz: understanding variation in family practices using complexity science. J Fam Pract 2001;50:872-8.

16. Crabtree BF, Miller WL, Stange KC. Understanding practice from the ground up. J Fam Pract 2001; 50:881-7.

17. Miller WL, Crabtree BF, McDaniel R, Stange KC. Understanding change in primary care practice using complexity theory. J Fam Pract 1998;46:369-76.

18. Stange KC, Goodwin MA, Zyzanski SJ, Dietrich AJ. Sustainability of a practice-individualized preventive service delivery intervention. Am J Prev Med 2003; 25:296-300.

19. Sussman A, Williams RW, Leverence R, Gloyd PW, Crabtree BF. The art and complexity of primary care clinicians' preventive counseling: obesity as a case study. Ann Fam Med 2006;4:327-33.

20. Ryan RM, Deci EL. Self-determination theory and the facilitation of intrinsic motivation, social development, and well-being. Am Psychol 2000;55:6878.

21. Landry JB, Solmon MA. Self-determination theory as an organizing framework to investigate women's physical activity behavior. Quest 2002;54:532-54.

22. Deci EL, Ryan RM. Intrinsic motivation and selfdetermination in human behavior. New York: Plenum; 1985.

23. Deci EL, Ryan RM. The "what" and "why" of goal pursuits: human needs and the self-determination of behavior. Psychol Inq 2000;11:227-68.

24. Vansteenkiste M, Sheldon KM. There's nothing more practical than a good theory: integrating motivational interviewing and self-determination theory. Br J Clin Psychol 2006;45:63-82.

25. Williams GC, McGregor HA, Zeldman A, Freedman ZR, Deci EL. Testing a self-determination theory process model for promoting glycemic control through diabetes self-management. Health Psychol 2004;23:58-66.

26. Williams GC, Lynch MF, Glasgow RE. Computerassisted intervention improves patient-centered diabetes care by increasing autonomy support. Health Psychol 2007;26:728-34.

27. Williams GC, McGregor H, Sharp D, et al. A selfdetermination multiple risk intervention trial to improve smokers' health. J Gen Intern Med 2006;21: 1288-94.

28. Miller WL, Crabtree BF. Depth interviewing. In: Crabtree BF, Miller WL, eds. Doing qualitative re- 
search. 2nd ed. Thousand Oaks (CA): Sage Publications, Inc.; 1999:89-108.

29. Crabtree BF, Miller W. Doing qualitative research. 2nd ed. Thousand Oaks (CA): Sage Publications, Inc; 1999.

30. NVivo [computer program]. Version 2. Doncaster, Victoria, Australia: QSR International; 2002.

31. Crabtree BF, Miller WL. Using codes and code manuals: a template organizing style of interpretation. In: Crabtree BF, Miller WL, eds. Doing qualitative research. 2nd ed. Thousand Oaks (CA): Sage Publications; 1999:163-78.

32. Stange KC. The paradox of the parts and the whole in understanding and improving general practice. Int J Quality Health Care 2002;14:267-8.

33. Stone EG, Morton SC, Hulscher ME, et al. Interventions that increase use of adult immunization and cancer screening services: a meta-analysis. Ann Intern Med 2002;136:641-51.

34. Greco PJ, Eisenberg JM. Changing physicians' practices. N Engl J Med 1993;329:1271-3.

35. Balas EA, Weingarten S, Garb CT, Blumental D, Boren SA, Brown GD. Improving preventive care by prompting physicians. Arch Intern Med 2000;160: 301-8.

36. Christensen RE, Fetters MD, Green LA. Opening the black box: cognitive strategies in family practice. Ann Fam Med 2005;3:144-50.

37. Leverence R, Williams RL, Sussman A, Crabtree BF. Obesity counseling and guidelines in primary care: a qualitative study. Am J Prev Med 2007;32: 334-9.

38. Perscription for Health National Program Office. Prescription for health [homepage on the Internet]. Available at http://www.prescriptionforhealth.org/. Accessed 25 June 2007.

39. Improving Chronic Illness Care. Improving chronic care [homepage on the Internet]. Available at http:// www.improvingchroniccare.org. Accessed 25 June 2007.

40. Williams GC, Levesque C, Zeldman A, Wright S, Deci EL. Health care practitioners' motivation for tobacco-dependence counseling. Health Educ Res 2003;18:538-53.

\section{Appendix 1. Clinician Interview Guide Introduction}

Thank you for taking the time to meet with me today. Your participation in this project will help us to understand how primary care clinicians handle the many competing demands during each brief outpatient encounter. We hope to use this information as a first step in developing evidence-based strategies for the brief encounter. The information that you provide will be kept strictly confidential as will the identity of every clinician interviewed for this study. Do you have any questions before we begin?

1. Please tell me about your practice (schedule, practice locations, types of patients, etc).

2. Can you share with me your most recent patient encounter?

a) Was preventive counseling a part of this encounter?

b) Was obesity an issue for this patient?

(if no) Can you recall the last obese patient you saw?

c) Did you discuss the patient's obesity?

If Yes:

a) Can you tell me about the factors that led to this dialogue?

b) What was your schedule like that day?

c) How effective was this intervention?

d) Can you share with me another encounter with a patient who was obese, and where obesity did not come up for discussion?

If No:

a) There are certainly lots of reasons why this topic might not come up. What were the reasons that obesity was not discussed on this visit? (What was your schedule like that day?)

b) Can you describe any particular challenges about the encounter that made it difficult to discuss the patient's obesity?

c) Some clinicians feel that counseling about obesity is not a productive use of time in most brief clinical encounters. How do you feel about delivering this service in your practice?

d) Can you share with me the most recent patient encounter where you did provide preventive health counseling related to obesity?

3. We are especially interested in times when the clinician discusses a patient's obesity. Can you say something about situations that lead to taking time in the brief encounter to talk about this?

4. Can you tell me about what other kinds of things influence whether or not obesity comes up for discussion with a particular patient?

a) How do things like scheduling or how your day is going affect this type of counseling?

5. Can you say something about how you decide the priorities of which issues to address in the brief encounter?

6. Thinking more broadly about patients that are obese/at-risk for diabetes, can you recall a case/ other cases where your preventive counseling efforts were successful? 
a) What factors were most important in this outcome?

b) How do you define success?

7. We are also interested in how your personal values pertaining to issues like lifestyle and health and wellness more generally may affect the intensity and frequency with which you provide counseling for obesity. How would you respond to this?

8. Can you please tell me about other types of preventive counseling that you provide in your practice?

a) How successful are these efforts?

b) Has your approach changed over time?
9. We are also interested in things external to the encounter-such as clinical guidelines, priorities in an organization or what other clinicians are saying about a particular clinical problem or how they are handling it. Can you tell us more about how these issues might come into play in deciding how to spend time in the encounter, thinking again about a patient with obesity.

- Guidelines

- Organizational

- Other clinicians

10. Are there any other issues pertaining to preventive counseling that you would like to discuss?

\section{Appendix 2: Results of Responses to Individual Survey Items}

1. Obesity can be viewed in a number of ways. Please rank the following statements in order according to how you view the problem of obesity. Obesity is best viewed as a disease, disorder, or illness amenable to medical intervention.

Obesity is best viewed as a more general syndrome, the result of complex interactions between heredity and the physical environment.

Obesity is best viewed as a matter of personal health and wellness, for which choices are strongly influenced by the emotional and relational domains of health.

2. The approach to obesity can also be viewed in a number of ways. Please rank the following statements in order according to how you view solutions to the problem of obesity.

Biomedical or technical advances (such as a pill) will ultimately offer the greatest benefit for prevention and treatment of obesity.

Although genetic and molecular research may hold promise, efforts addressing environmental and socioeconomic factors will have the greatest benefit for prevention and treatment of obesity.

Approaches favoring personal health and wellness will have the greatest benefit for prevention and treatment of obesity.

3. Under what conditions or for which patients do you discuss obesity? Check all that apply.

All visits.

All well-child checks or annual exams.

Patients at risk for obesity or diabetes.

Teachable Moments-when presented with a condition affected by their obesity.

When a patient or family member wishes to discuss it.

I rarely discuss it.

Other.

\begin{tabular}{ccr} 
& Rank (\%) $(\mathrm{n}=\mathbf{1 4 6})$ & \\
\hline 1st & 2nd & 3rd \\
6 & 14 & 80 \\
68 & 26 & 6 \\
28 & 58 & 14
\end{tabular}

$\begin{array}{rrr}4 & 11 & 85 \\ 58 & 37 & 5 \\ 41 & 50 & 9\end{array}$

$\%(n=146)$

21

60

90

94

88

0

5 


\section{Continued}

4. Compared with other issues in the clinical encounter, I may choose not to spend time on counseling about obesity because:

Patients are not receptive to discussing this topic

I don't feel it is time well spent.

I don't have much success with this.

It is a societal problem that my efforts have little impact on.

Few patients are motivated to make the lifestyle changes needed.

There isn't enough time.

I don't feel like I have the skills or knowledge needed to be effective in this area.

My patients generally do not have the personal or community resources to be able to deal with this.

5. I spend time on counseling about obesity because:

I have had some success with this in the past.

It is recommended by clinical guidelines.

My patients are unlikely to hear a similar message elsewhere.

Interactions with my colleagues have influenced me to do so.

Because of my personal belief that the nonobese have a significantly better quality of life.

6. Which of the following is most important in your decision to spend time counseling about obesity.

I have had some success with this in the past.

It is recommended by clinical guidelines.

My patients are unlikely to hear a similar message elsewhere.

Interactions with my colleagues have influenced me to do so.

Because of my personal belief that the nonobese have a significantly better quality of life.

7. In treating obese patients, I consider a successful outcome to be (please choose one):

The patient must lose sufficient weight to have a BMI under 30 .

The patient should progressively decrease weight, if only in small amounts.

A total weight loss of 5 to 10 lbs.

No additional weight gain.

Any positive change in health habits, even if there continues to be a slight increase in weight.

Other.

8. More time in my schedule would allow me to have a meaningful impact on obesity in my practice:

9. More clinic resources (e.g., dieticians or promotoras) would allow me to have a meaningful impact on obesity in my practice:

10. Counseling regarding obesity is important in my practice:

11. Compared with other issues I must take care of in the brief clinical encounter, I give counseling regarding obesity a high priority:
Location of mark on visual analogue scale, where strongly disagree $=0$ and strongly agree $=100$, mean $(\mathrm{SD})(\mathrm{n}=143)$
$41.2(24.2)$
$23.0(23.4)$
$50.0(24.4)$
$30.0(24.8)$
$48.0(23.4)$
$52.6(24.4)$
$28.9(22.5)$
$48.1(26.9)$

Location of mark on visual analogue scale, where strongly disagree $=\mathbf{0}$ and strongly agree $=100$, mean $(S D)(n=142)$

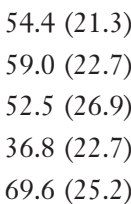

$\%(n=135)$

12

12

10

64

$\%(n=138)$

1

38

4

10

43

4

Location of mark on visual analogue scale, where strongly disagree $=0$ and strongly agree $=100$, mean (SD)

$$
\begin{aligned}
& 51.4(23.1)(\mathrm{n}=142) \\
& 74.2(22.1)(\mathrm{n}=140) \\
& 74.4(18.6)(\mathrm{n}=142) \\
& 65.0(20.1)(\mathrm{n}=142)
\end{aligned}
$$


12. Please rank the following statements, according to which is likely to have the most influence on the prevention of obesity:

Improvement of my counseling skills.

Enhancement of clinic support services (e.g., dieticians or promotoras).

Join advocacy efforts aimed at legislation, communities, and schools.

13. Do you currently participate in community outreach, advocacy or legislative efforts regarding obesity

Yes

How likely are you to devote time to these types of activities if a coordinated program were available in your local or regional healthcare community?

Not likely at all.

Somewhat likely.

Very likely.

14. The following would be useful to me in trying to increase my effectiveness in counseling for obesity prevention and treatment:

Education for counseling on specific diets.

Training on brief motivational counseling to increase my ability to help patients become ready to make lifestyle changes.

15. Based on our interviews with clinicians around the state, we have identified several considerations that are important to providers in making the decision about whether to spend time on counseling for obesity prevention in the brief clinical encounter. Please review this list and indicate in order of priority which of these is generally most important for you in determining whether to spend time with a patient on this topic. (1 = most important, etc.)

Acute vs. well-care visit.

Patient agenda.

Presence/absence of teachable moment.

Perceived receptivity of patient to discussion.

Whether the patient is pediatric or adult.

Recent experiences I have had dealing with this topic.

My views about what would be best for this patient's overall health and well-being.

\begin{tabular}{lcr}
\multicolumn{3}{c}{ Rank (\%) $(\mathbf{n = 1 4 3 )}$} \\
\hline 1st & 2nd & 3rd \\
& & \\
10 & 24 & 66 \\
39 & 52 & 8 \\
56 & 20 & 24 \\
& \% $(\mathbf{n}=\mathbf{1 4 5})$ &
\end{tabular}

\section{1 \\ $\%$ \\ 17 \\ 64 \\ 18}

Location of mark on visual analogue scale, where strongly disagree $=\mathbf{0}$ and strongly agree $=100$, mean $($ SD)
$57.3(27.1)(\mathrm{n}=138)$
$69.7(21.8)(\mathrm{n}=140)$ 